An improved method of banking the donor material at low temperature is described, entailing the immersion of the cornea with an attached rim of sclera in medium containing dimethyl sulphoxide. The storage temperature is that of liquid nitrogen $\left(-196^{\circ}\right.$ C. $)$ instead of that of solid carbon dioxide $\left(-79^{\circ} \mathrm{C}.\right)$, as formerly used.

Though the results with deep-frozen donor material were superior to those with fresh material, many further trials will be needed before this apparent superiority of frozen material can be established. But it can reasonably be concluded that deepfreezing provides a satisfactory method of preservation, and should eliminate the present wastage of this valuable donor material.

The work was jointly supported by the "Action for the Crippled Child" Fund, London, and by the Haile Selassie I Foundation, Addis Ababa ; to these, and to the Medical Research Council, who supported all our preliminary investigations, we are greatly indebted. We must also thank Professor E. C. Amoroso and Professor G. Formston, of the Royal Veterinary College, from whose premises we operated; and the Governors of Westminster Hospital and Moorfields Eye Hospital, who provided us with the services of the Westminster-Moorfields Eye Bank. Many individual members of these hospitals gave us constant assistance, particularly Mr. Baker and his staff in the Pharmaceutical Department and Dr. Hansell's Medical Illustration Department at Westminster.

We would like to acknowledge more personally the assistance given by Ato Melesse Nazir, by Sister Macdesse Gizaw and Sister Kenya Gizaw at the Haile Selassie I Hospital ; Dr. Paulos Quana, ophthalmologist to the Menelik II Hospital in Addis Ababa ; and Dr. Hudson Silva, who provided so many fresh eyes from the Ceylon Eye Donation Society's Eye Bank in Colombo.

We are also grateful to Union Carbide Linde Division, the Metal Box Co., and Rayner \& Keeler Ltd., who provided us with necessary equipment.

\section{REFERENCES}

Eastcott, H. H. G., Cross, A. G., Leigh, A. G., and North, D. P. (1954). Lancet, 1, 237.

Fiordbotten, A. L. (1965). The Cornea. Butterworths, London.

Mueller, F. O., Casey, T. A., and Trevor-Roper, P. D. (1964). Brit. med. f., 2, 473.

O'Neill, P., Muelle, F. O., and Trevor-Roper, P. D. (1966). In preparation.

Rycroft, B. W. (1955). Corneal Grafts. Butterworths, London.

Smith, A. U. (1965). In The Cornea, p. 384. Butterworths, London. Smith, A. U. (1965). In The Cornea, p.

\title{
Histopathological Changes in the Foetal and Infantile Inner Ear Caused by Maternal Rubella*
}

\author{
I. FRIEDMANN, $\dagger$ M.D., D.C.P., F.C.PATH. ; M. I. WRIGHT, $\ddagger$ M.R.C.S., L.R.C.P., D.C.P., M.C.PATH.
}

[With Special Plate]

Brit. med. F., 1966, 2, 20-23

The special vulnerability of the eye, ear, and heart of the developing foetus in maternal rubella during the first trimester of pregnancy is now well recognized (Gregg, 1941; Swan, Tostevin, Moore, Mayo, and Black, 1943).

The incidence of deafness in maternal rubella, however, cannot be exactly determined, as there is some variation in the figures given by various authors (Manson, Logan, and Loy, 1960 ; Barr and Lundstrom, 1961 ; Rendle-Short, 1964 ; Fraser, 1964 ; Lamy, 1964 ; and others).

Sheridan (1964), on the basis of one of the best prospective inquiries by Manson et al. (1960) for the Ministry of Health, concluded that major abnormalities, mainly of the eye, ear, and heart, occurred in $15 \%$ of children of mothers who had rubella in the first weeks of pregnancy. Rendle-Short (1964) suggested that deafness might occur in $50 \%$ of affected children, but may be only partial. These inquiries have shown up very clearly the importance of rubella in early pregnancy as a cause of congenital deafness and the need for long-term followup and periodic full reassessment of children known to be at risk from maternal rubella during the first 16 weeks of pregnancy, as recommended by Fisch (1955).

It has become even more important since modern virological and serological methods have furnished additional evidence of the profound teratogenic role of clinical as well as subclinical rubella infections. These are bound to affect our thinking on the part played by the rubella virus in the causation of profound

\footnotetext{
* This paper is based on lectures given by one of us (I. F.) at the Departments of Otolaryngology of Iowa University, the Mount Sinai Hospital, New York, Yale University, and the Massachusetts Eye and Ear Hospital.

† Professor of Pathology, University of London.

I Sening Lecturer in Clinical Pathology, University of London.
}

childhood deafness (Alford, Neva, and Weller, 1964 ; Dudgeon, Butler, and Plotkin, 1964 ; Plotkin, Oskin, Hartnett, Hervada, Friedman, and Gowing, 1965 ; Lambert, Stern, and Wellstead, 1965).

In contrast with the rapid progress of the epidemiology and virology of rubella, new knowledge of the histopathology of rubella deafness has remained fragmentary, owing to the relatively small number of available temporal-bone specimens. The first case was described by Carruthers in 1945. Schall, Lurie, and Kelemen (1951) and Kelemen and Gotlib (1959) studied the temporal bones of embryos removed from mothers who had suffered from rubella during the first three months of pregnancy. There was extensive haemorrhage in the inner ear; this finding was incriminated as the main cause of arrested development of the auditory apparatus.

Nager (1952) described the temporal bones from three children; in two these showed definite malformations, and in the third they showed only partial damage of the inner ear.

Gray (1959) studied the inner ear of a $53-\mathrm{mm}$. foetus whose mother developed rubella on the 37th day of pregnancy ( 51 days after L.M.P.). The principal lesion seemed to be a lysis of the epithelium of the organ of Corti leading to disappearance of the sensory cells.

The clearest description of the histopathological changes was given by Lindsay, Carruthers, Hemenway, and Harrison (1953), who examined the inner ears of four children exposed to maternal rubella in the early months of pregnancy. It is interesting to note that only one of the children who had suffered from severe bilateral deafness and died at the age of 5 years showed bilateral cochleo-saccular degeneration.

The findings were interpreted as the direct effect of the rubella virus upon the vascular stria, affecting the endolymph and the 


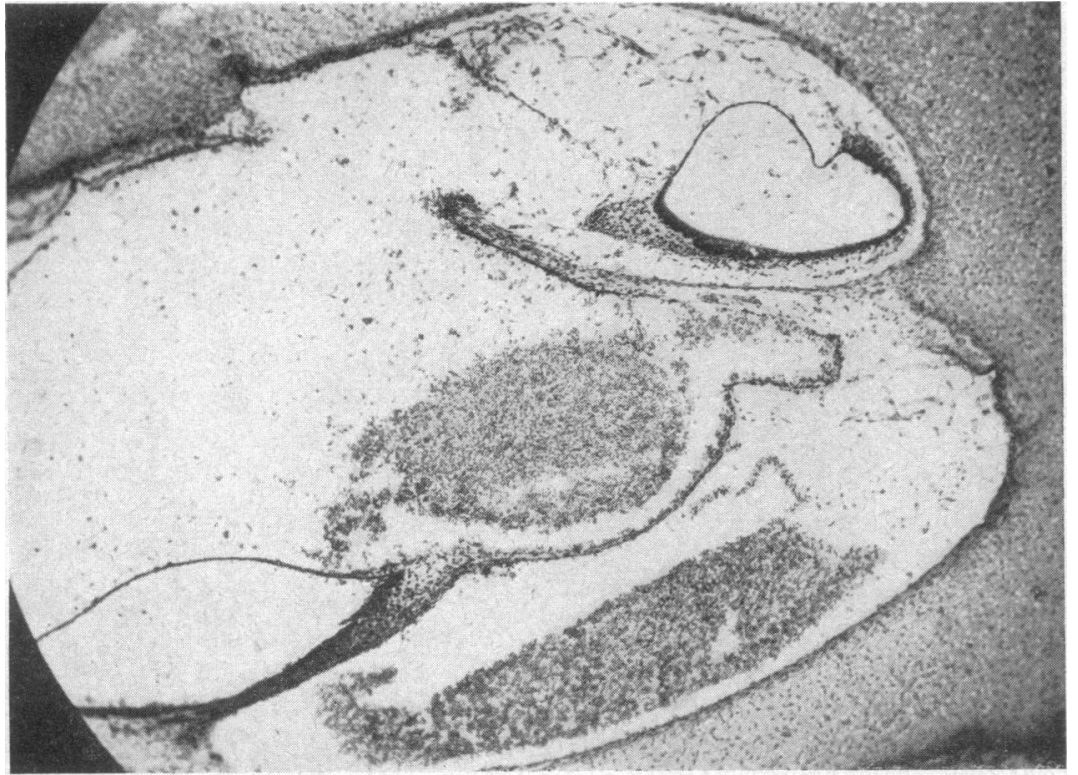

FIG. 2.-Case 2. Detail of foetal cochlea showing the middle coil and moderately well differentiated organ of Corti ; note spiral limbus, tectorial membrane and Reissner's membrane. Vascular stria consists of a layer of cuboidal cells. There is much fresh blood in the scala vestibuli and some mesenchymatous
scala tympani. $(\times 90$.

Fig. 1.-Case 1. Survey picture of foetal cochlea showing the apical coil ; note the tunnel space in the differentiating organ of Corti-less clearly visible in the basal coil. There is much haemorrhage in the scala tympani of the basal coil and also in the mesenchymatous tissue of the modiolus. $(\times 35$.)
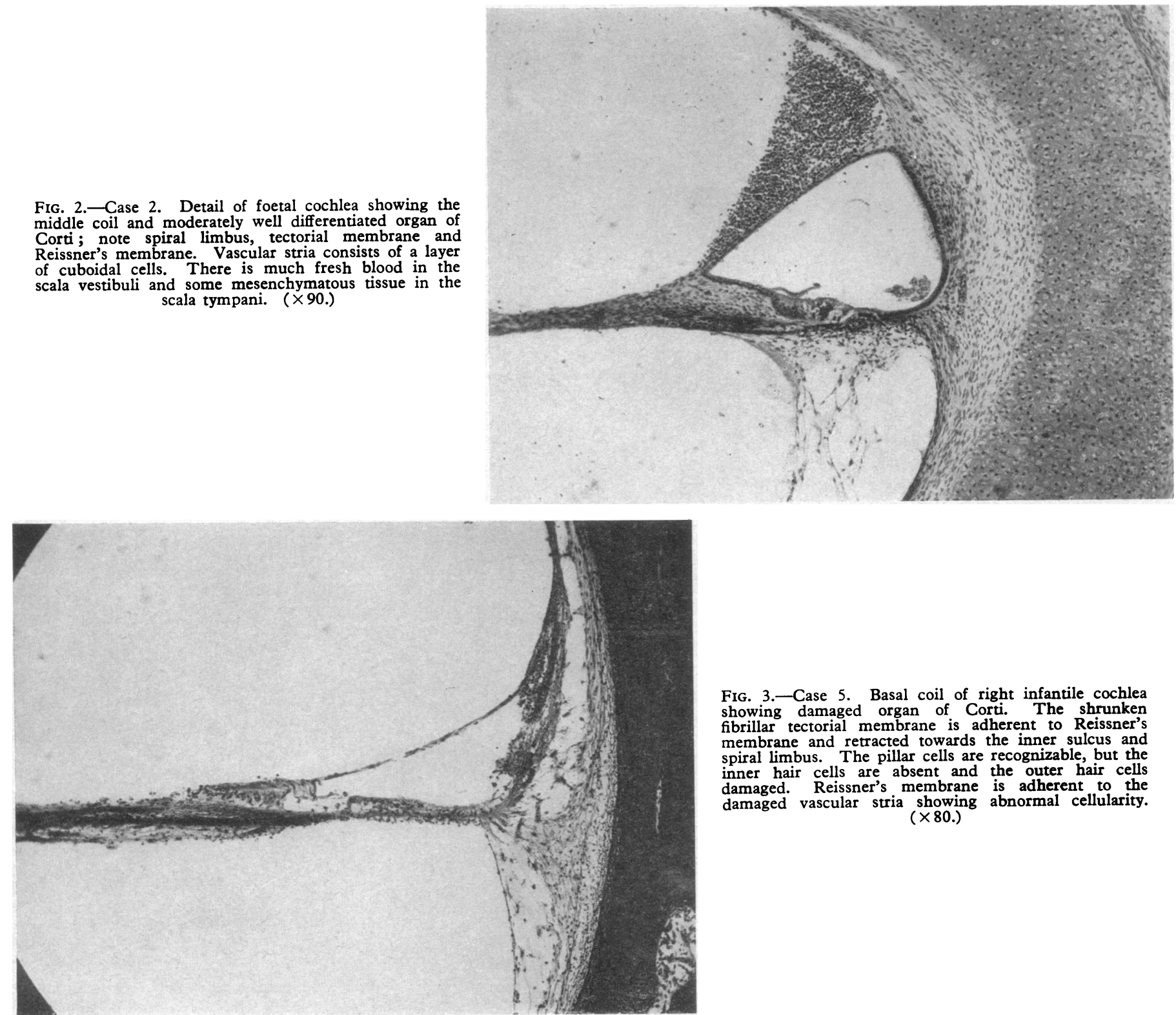

Fig. 3.-Case 5. Basal coil of right infantile cochlea showing damaged organ of Corti. The shrunken fibrillar tectorial membrane is adherent to Reissner's membrane and retracted towards the inner sulcus and spiral limbus. The pillar cells are recognizable, but the spiral limbus. The pillar cells are recognizable, bair cells damaged. Reissner's membrane is adherent to the damaged vascular stria showing abnormal cellularity. $(\times 80$. 
I. FRIEDMANN AND M. I. WRIGHT: CHANGES IN INNER EAR CAUSED BY MATERNAL RUBELLA

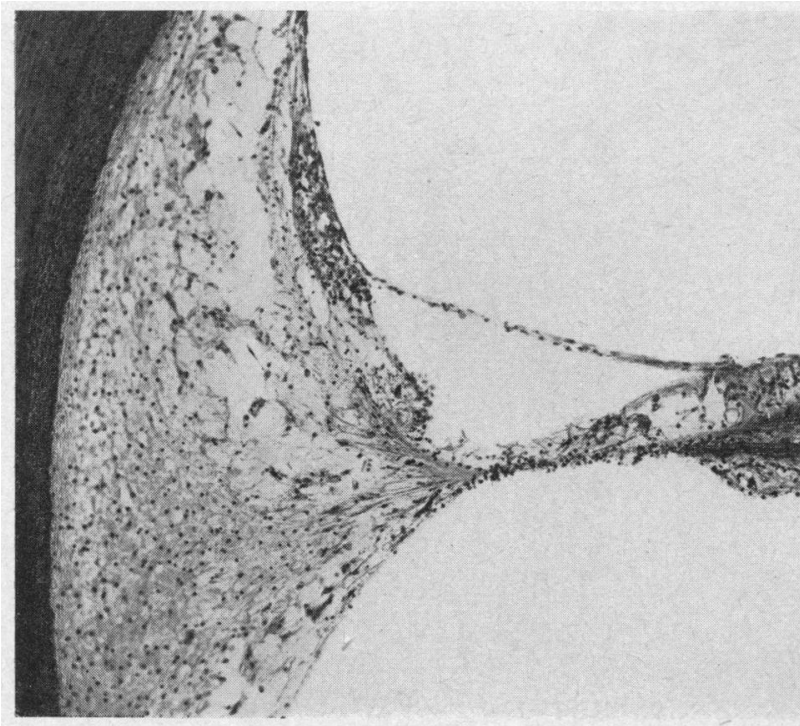

FIG. 5.-Case 6. The basal coil of the right infantile cochlea ; note inflammatory cellular infiltration on the tympanic surface of the basilar membrane and congested spiral ligament. Reissner's membrane is adherent to the atrophic vascular stria and to the spiral limbus, and the distorted and retracted tectorial membrane forms a misshapen structure underneath the adherent Reissner's membrane. $(\times 50$.)
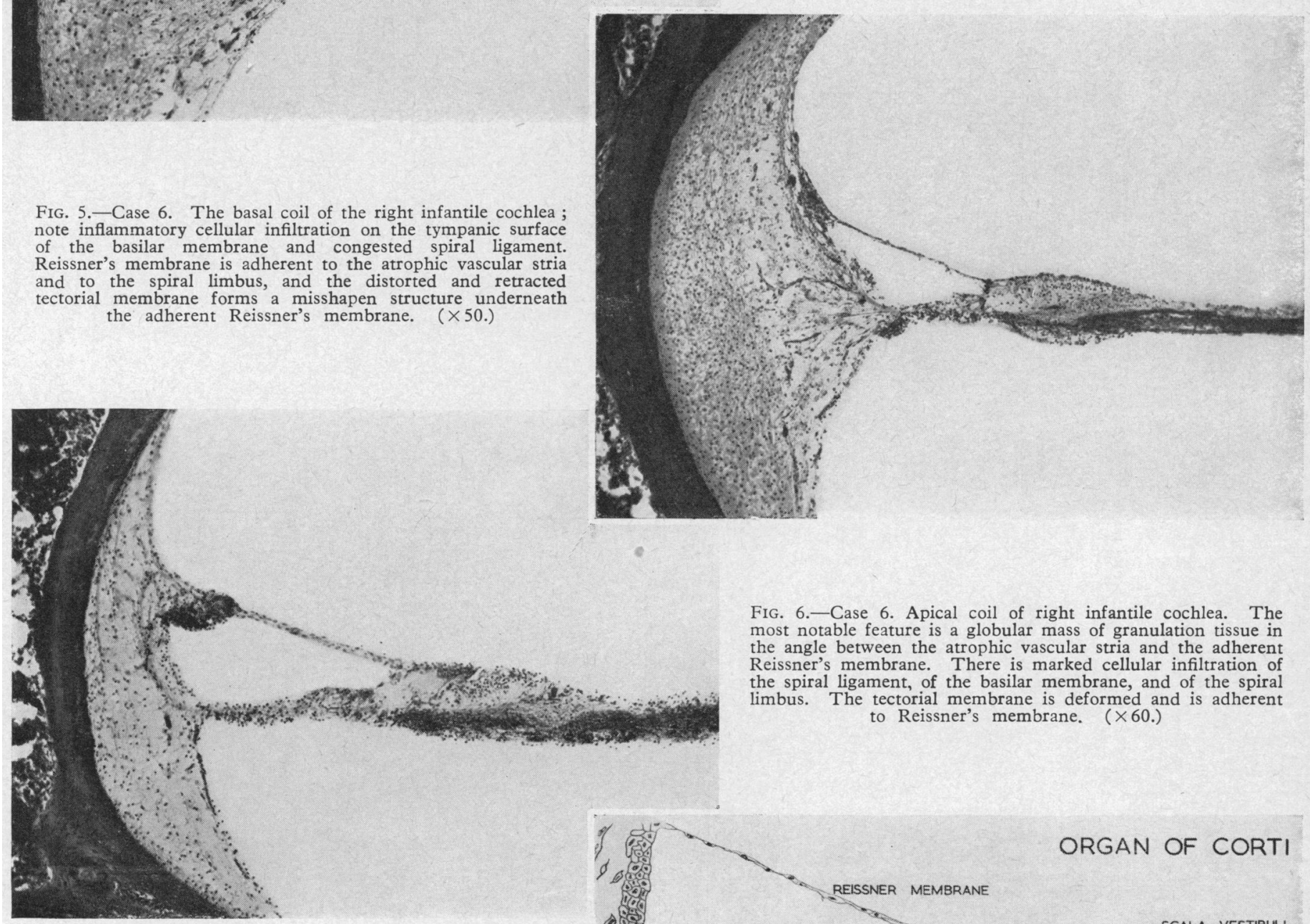

FIG. 4.-Case 5. Middle coil of right infantile cochlea showing vascular stria densely infiltrated by inflammatory cells. Reissner's membrane is adherent to the inflamed vascular stria. The organ of Corti is deranged, though the pillar cells are recognizable; the outer hair cells can also be seen but not the inner hair cells. $(\times 87$.

FIG. 6.-Case 6. Apical coil of right infantile cochlea. The most notable feature is a globular mass of granulation tissue in the angle between the atrophic vascular stria and the adherent Reissner's membrane. There is marked cellular infiltration of the spiral ligament, of the basilar membrane, and of the spiral limbus. The tectorial membrane is deformed and is adherent to Reissner's membrane. ( $\times 60$.)

FIG. 7.-Normal human organ of Corti. $(\times 160$.

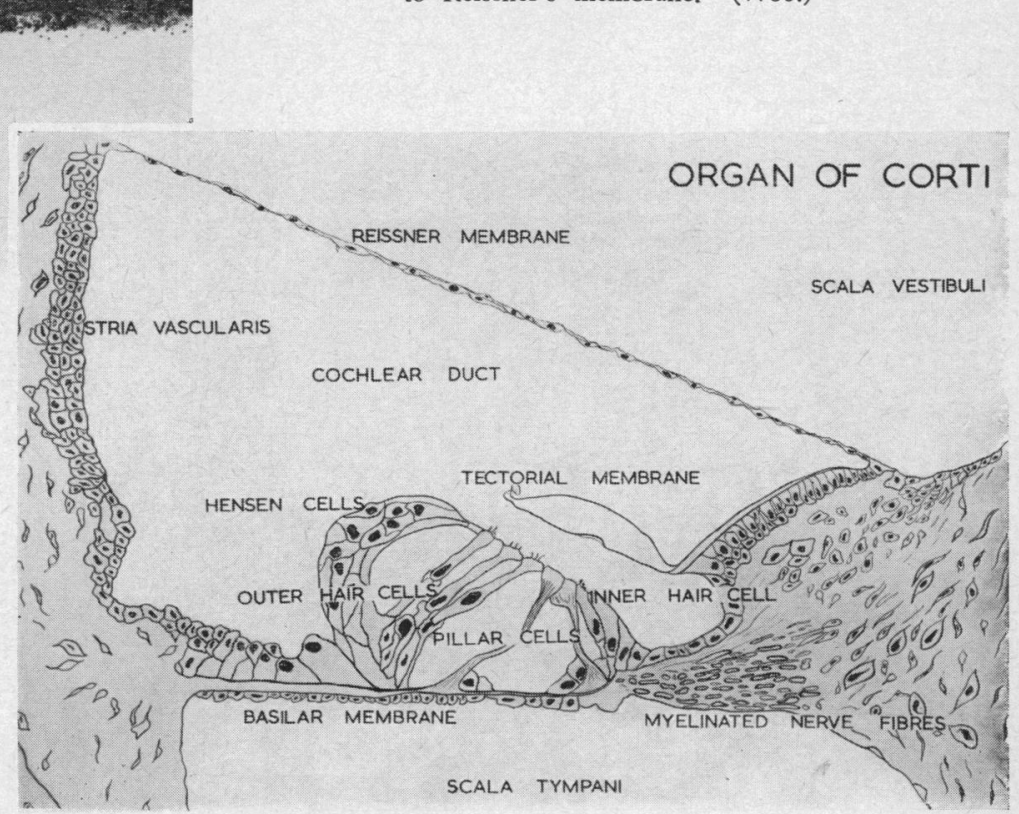


epithelium of the coshlear duct and leading to depression and collapse of Reissner's membrane, a derangement of the tectorial membrane, and direct interference with the differentiation of the organ of Corti.

The present paper is based on the histopathological study of five foetal skulls, one of which proved unsuitable owing to poor fixation, and of four temporal bones from two infants whose mothers had suffered from rubella during the early stages of pregnancy.

\section{Material Studied}

Through the cooperation of several colleagues ${ }^{1}$ numerous specimens were obtained, and included the skulls of five foetuses (Cases 1, 2, 3, and 4), one foetal skull proving unsuitable owing to poor fixation; and both temporal bones of two infants (Cases 5 and 6). The specimens were fixed in formol-saline as soon after hysterotomy or induced abortion and post-mortem examination as possible and posted to this department, where they were processed and embedded into low-viscosity nitrocellulose by a standard method used in our Temporal Bone Laboratory.

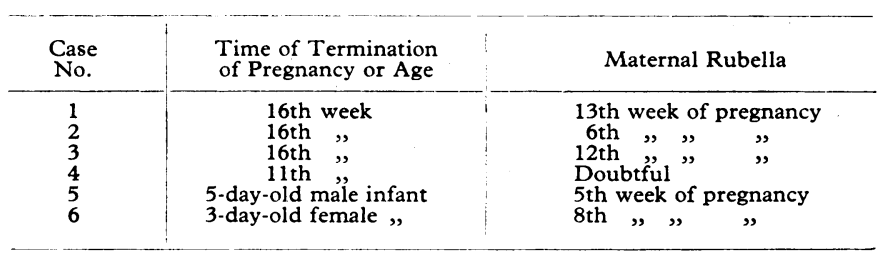

\section{Foetal Cases}

\section{Case 1 (Special Plate, Fig. 1)}

Clinical History.-Mother had rubella at 13 th week of pregnancy, which was terminated by hysterotomy at the 16th week. There were no previous children.

Post-mortem Findings.-Cochlea:-The well-developed cochlea was surrounded by the cartilaginous otic capsule. There was a good deal of haemorrhage in the cochlea (more pronounced on the right side), affecting the scalae but mainly the mesenchymatous tissue of the modiolus. Organ of Corti:-This consisted of columnar epithelium showing signs of differentiation and was covered by the tectorial membrane. The vascular stria was thin and covered by a single layer of cuboidal to columnar cells. The tunnel of Corti was formed and patent in the apical coil. The pillar cells were recognizable. Vestibular Apparatus:-There was full differentiation of the neuroepithelium of the maculae. Cristae were apparently normal.

\section{Case 2 (Special Plate, Fig. 2)}

Clinical History.-Mother had rubella at the 6th week of pregnancy. Husband had rubella 20 days earlier. Therapeutic abortion was carried out at the 16 th week of pregnancy.

Post-mortem Findings.-Apparently normal foetus.

Histopathology.-Cochlea:-The well-developed cochlea was surrounded by the cartilaginous otic capsule. Internal auditory meatus was visible. Organ of Corti:-This consisted of columnar epithelium showing some differentiation of the sensory cells and of the pillar cells. The tectorial membrane and Reissner's membrane were normal. The vascular stria was covered by cuboidal cells. There was some haemorrhage in the cochlea, mainly in the scala vestibuli. Vestibular Apparatus:-There was full differentiation of the neuroepithelium of the maculae and the cristae.

' Our sincere thanks are due to Dr. F. A. Langley, consultant pathologist, Manchester, for Cases 1, 2, and 3 ; to Dr. M. Crawfurd, Galton Laboratory, University College Hospital Medical School, for Case 4 to Mr. E. N. Owen, consultant E.N.T. surgeon, and Dr. E. Ross, pathologist, Shrewsbury, for Case 5 ; and to Mr. B. E. Blair, consultant gynaecologist, and Dr. R. L. Bishton, pathologist, Bath, for

\section{Case 3}

Clinical History.-Mother had rubella at the 12 th week of pregnancy. Her youngest child had rubella a short time before the mother contracted the disease. The foetus was delivered by abdominal hysterotomy at the 16 th week of pregnancy. The crownrump length of this foetus was $9 \mathrm{~cm}$.

Histopathology.-Cochlea:-Fully developed and surrounded by a cartilaginous otic capsule. Organ of Corti:-This consisted of damaged columnar epithelium showing cellular infiltrate. The tectorial membrane appeared to be normal. The blood-vessels were congested but there was no obvious haemorrhage. Vascular stria was formed by simple cuboidal epithelium resting on fibrous tissue. Vestibular Apparatus:-There was well-differentiated neuroepithelium of maculae and cristae.

\section{Case 4, 11-weeks-old foetus}

Clinical History.-Mother was supposed to have had German measles during pregnancy.

Post-mortem Findings.-No external or inteinal abnormality was observed.

Histopathology.-Cochlea:-Both sides were fully developed. Otic capsule showed signs of ossification. Organ of Corti:- This showed complete differentiation. There was no evidence of haemorrhage. Vestibular Apparatus:-Maculae and cristae showed fully differentiated neuroepithelium with otolithic membrane and cupula respectively. Eighth Nerve:-Normal.

\section{Infantile Cases}

Case 5, 5-day-old male infant (Special Plate, Figs. 3 and 4)

Clinical History.-Mother had rubella at the fifth week of pregnancy. Normal birth. Found to have loud hard systolic murmur and left cataract. Condition at birth was poor and it slowly deteriorated.

Post-mortem Findings.-Heart was considerably enlarged owing to hypertrophy and dilatation of right auricle and ventricle, especially the former. Ductus arteriosus was widely patent. All other organs were normal.

Histopathology.-Cochlea:-The most significant damage was shown in the basal coil. The depressed Reissner's membrane was adherent to the stria and the spiral lamina. The condition of the tectorial membrane was especially significant in that it had been retracted away from the organ of Corti and was covered, at least in part, by a cellular membrane. The substance of the tectorial membrane seemed well preserved but the shape was disturbed. The pillar cells were abnormal-possibly a developmental defect. The hair cells of Corti's organ were present, though not clearly orientated. The stria showed some evidence of degenerative change. Saccule:-The saccular wall was depressed, but on one side was not adherent to the macula such as might be anticipated in this type of pathological disturbance.

Case 6, 3-day-old female infant (Special Plate, Figs. 5 and 6)

Clinical History.-Mother had rubella at the eighth week of pregnancy. The auditory reflexes of the child in utero were tested at 34 weeks' gestation and found to be reasonably commensurate with a normally developed auditory apparatus. Shortly after birth the infant developed a petechial rash and slight jaundice which could not be accounted for at necropsy. The infant died when 3 days old.

Hisopathology.-Cochlea:-Well developed. Organ of Corti:The main lesion was in the vascular stria, where a good deal of cellular granulation tissue was present, which formed globular granulomatous structures that protruded into the cochlear duct and formed adhesions with Reissner's membrane. The sensory epithelium and the pillar cells formed an irregular mound of degenerating cells. The fibrillar or laminated tectorial membrane was deformed and shrunken throughout the cochlea and could be found lying rolled up on the surface of the spiral limbus, or retracted into the inner sulcus. There was marked lymphocytic infiltration of the basilar membrane. The lesion was more advanced in the apical 
coil, but also the middle and basal coils showed obvious inflammatory and degenerative changes. Vestibular Apparatus:Apparently normal.

\section{Discussion}

The unambiguous biological classification of deafness is fraught with much difficulty, especially that of congenital deafness and deaf-mutism, a term that should better be replaced by the term profound childhood deafness, as suggested by Fraser (1964).

Profound childhood deafness is frequently due to genetical causes. Thorough clinical, genetical, and statistical studies have done much to provide a reasonably accurate picture of the spectrum of causes of profound childhood deafness as a whole, and informed estimates can be made of their relative importance (Fraser, 1964). Exogenous causes, however, cannot be ignored, and the role of the rubella virus has attracted particular interest. Histopathological studies of the inner ear in deafness caused by rubella as well as by other factors have, however, been hampered by the shortage of suitable specimens.

The present observations are based on the microscopical study of four foetal skulls, and, in particular, on four temporal bones of two infants-a 5-day-old male infant whose mother had rubella in the fifth week of pregnancy, and a 3-day-old female infant with maternal rubella in the eighth week of pregnancy.

Other signs of rubella embryopathy included, in the 5-day-old male infant (Case 5), cardiac hypertrophy and a widely patent ductus arteriosus. There was a left cataract and the condition at birth was poor. The 3-day-old female infant (Case 6) developed a petechial rash and slight jaundice after birth, forming part of the expanded rubella syndrome. The auditory reflexes in utero at 34 weeks' gestation suggested a normally developed auditory apparatus.

Deafness in the newborn may be caused by failure to develop one or more parts of the auditory system or by an interruption at any stage of the progress of development. It may also be due to some process such as infection with the rubella virus, which may disturb or cause to degenerate the already wholly or partly developed hearing mechanism (Ormerod, 1960). It has been assumed that the rubella virus was primarily responsible for an interruption of the development of the auditory apparatus at an early stage.

The principal pathological finding in the embryonic inner ear following maternal rubella consists of haemorrhage into the scalae and into the mesenchymatous modiolus (Schall et al., 1951 ; Kelemen and Gotlib, 1959) which, it has been assumed, might cause irreparable damage to the developing auditory organ.

In two of the foetal cases presented (Cases 1 and 2) there was a good deal of haemorrhage in the cochlea, yet the neuroepithelial structures showed fairly advanced signs of differentiation both of the organ of Corti and of the vestibular apparatus. There was no obvious haemorrhage in the third foetal case. The vascular stria in all cases was invested by a simple cuboidal or flattened epithelium, and the tectorial membrane formed a normal membraneous structure extending over the differentiating cells of the organ of Corti. The fourth foetal case has been included, although the history of maternal rubella was doubtful. The inner ear showed complete differentiation of the organ of Corti and of the maculae and cristae. The ciliated hair cells in particular were clearly visible. There was no haemorrhage in this case either.

The consequential significance of the haemorrhagic component has been emphasized by Kelemen and Gotlib (1959), but doubted by Lindsay and Harrison (1954). It is interesting to note in this connexion that the rubella virus has recently been isolated from patients with thrombocytopenic purpura (Plotkin, 1964 ; Monif, Avery, Korones, and Sever, 1965). Yet the possibility of asphyxia being the cause of the microscopic extravasates of blood cannot be ruled out.
The histopathological findings in the infantile inner ear, described by Lindsay et al. (1953) and in our own two cases (Nos. 5 and 6), are of great interest, showing that the organ of Corti has reached morphological maturation. We have interpreted the lesions as consistent with degeneration of the preformed neuroepithelial structures, which in our opinion reflects continued virus-cell interaction, as suggested for other stigmata of the rubella syndrome.

The recovery of the rubella virus from the organs of infants aged $4 \frac{1}{2}$ to 9 months with the rubella syndrome demonstrates the internal persistence of a chronic state of infection in the congenital form of the disease (Alford et al., 1964; Monif et al., 1965 ; Lambert et al., 1965 ; Plotkin et al., 1965). It might be responsible for the disseminated pattern of the syndrome, including deafness.

There is some presumptive evidence in the infantile cochlea (Cases 5 and 6) of the activity of the virus in the vascular stria in the shape of large inflammatory granulations protruding far into the scala media and causing adhesions between Reissner's membrane and the vascular stria. There were no periodic-acidSchiff-positive deposits present, noted in the vascular stria of patients suffering from the cardio-auditory syndrome of Jervell and Lange Nielsen (Friedmann, Fraser, and Froggatt, 1966). The tectorial membrane has greatly suffered in both cases, to form a fibrillar shrunken structure retracted into the inner spiral sulcus or rolled up and resting on the spiral limbus.

There can be no doubt that these derangements of the tectorial membrane would affect the proper functioning of the underlying auditory neuroepithelium. Moreover, the damaged vascular stria may cease to participate in the circulation and biochemical control of the endolymph. In fact it may cause the scala media to dry up and Reissner's membrane to collapse and so become adherent to the degenerating remnants of the organ of Corti, suspending its function. The degeneration of the neuroepithelium may thus be entirely secondary to the inflammatory process affecting the structures of the cochlear duct.

Bosher and Hallpike (1965), on the basis of a study of the histopathological features, development, and pathogenesis of the inner-ear degeneration in the deaf white cat, believed that the degeneration of the inner ear may be due to a derangement of the water-electrolyte-regulating mechanism of the inner ear ; this in turn might result from the pathologically altered conditions of the scala media. This and other recent findings are bound to affect our thinking on the role of clinical as well as subclinical rubella in the causation of profound childhood deafness.

In our opinion it can be postulated not only that the rubella virus acted by arresting the development of the auditory apparatus but that it continued to be active in the cells of the developing or more fully developed auditory organ. Disturbance of the genes has been suggested by Wiedemann (1964); but no chromosomal abnormality was found by Selzer (1963) in cells of a foetus from whom the rubella virus had been isolated.

Kerr Love (1911) and Fraser (1964) rightly emphasized that the problems of deafness are deeper and more complex, if not more important, than those of blindness. Deafness is a much worse misfortune, for it means loss of the most vital stimulusthe sound of the voice-that brings language, sets thoughts astir, and keeps us in the intellectual company of man. These thoughts may help to understand the tremendous effort and ingenuity that has been directed and is still required towards the solution of the causes of deafness.

The present investigations were carried out before the discovery of suitable methods of isolating the rubella virus, which has given rise to a new concept of active infection on the foetus and in the newborn infant (Weller, Alford, and Neva, 1964 ; Dudgeon et al., 1964 ; Stern, 1965). It is obvious and imperative that in future every effort should be made to verify or 
exclude the role of the rubella virus in all cases of profound childhood deafness by means of modern virologicai and serological methods.

\section{Sumreary}

The histopathology of the embryonic and infantile inner ear following maternal rubella has been studied. This investigation has confirmed that there may be a good deal of haemorrhage prcsent in the foetal cochlea, but this finding appeared to be absent in two of the four cases examined. The cause of haemorrhage in the foetal inner ear is not clearly understood, but we are inclined to support the view that the haemorrhage is of asphyxial origin. Furthermore, the morphological differentiation of the organ of Corti seemed to be as advanced as could be expected. The state of differentiation of the organ of Corti was normal in the two infantile cases examined. There were profound inflammatory changes in the vascular stria, representing, it is suggested, the primary lesion caused by the rubella virus followed by secondary degenerative changes in the cochlear duct and organ of Corti which would certainly have resulted in profound childhood deafness. We may therefore regard the rubella virus as capable of causing profound childhood deafness later in foetal life than formerly, or even in post-natal life.

This study has been carried out with the invaluable and skilful assistance of Miss V. F. Shepherd. The work has been aided by a grant from the Nuffield Foundation to one of us (M.I.W.), which is gratefully acknowledged. Dr. J. R. Lindsay, Director, Otolaryngology Department, Chicago University, has very kindly reviewed the sections of Case 5 which have been included in a demonstration panel of the American Deafness Research Foundation and in the demonstration "Syndromes of Deafness" from this Institute by L. Fish and C. Connolly (B.M.A. Annual Scientific Exhibition in Swansea, 1965).
The Department of Pathology and Bacteriology, the Institute of Laryngology and Otology, 330 Gray's Inn Road, London W.C.1, would be glad to receive specimens of temporal bones from cases with a history of maternal rubella or from cases where the rubella virus was isolated.

REFERENCES

Alford, C. A., Neva, F. A., and Weller, T. H. (1964). New Engl. F. Med., 271,1275 .

Barr, B., and Lundstrom, R. (1961). Acta otolaryng. (Stockh.), 53, 413. Bosher, S. K., and Hallpike, C. S. (1965). Proc. roy. Soc. B, 162, 147. Carruthers, D. G. (1945) Med. f. Aust., 1 , 315.

Dudgeon, J. Butler, N. R., and Plotkin, S. A. (1964). Brit. med. Y., 2, 155 .

Fisch, L. (1955). 尹. Laryng., 69, 479.

Fraser, G. R. (1964). F. med. Genet., 1, 118.

Friedmann, I., Fraser, G. R., and Froggatt, P. (1966). F. Laryng. In press.

Gray, J. E. (1959). Ann. Otol. (St. Louis), 68, 170.

Gregg, N. M. (1941). Trans. ophthal. Soc. Aust., 3, 35

Kelemen, G., and Gotlib, B. N. (1959). Laryngoscope (St. Louis), 69, 385.

Lambert H. P Stern, H, and Wellsteed, A. J. (1965). Laecet, 2, 826.

Lamy, M. (1964). Lancet, 2, 88 .

Lamy, M. (1964). Lancet, 2, 88. G., Hemenway, W. G., and Harrison, M.' S. (1953). Ann. Otol. (St. Louis), 62, 1201.

and Harrison, M.S. (1954). F. Laryng., 68, 461.

Love, J. K. (1911). The Deaf Child. Wright, Bristol.

Manson, M. M., Logan, W. P. D., and Loy, R. M. (1960). Minist. Hith Rep. Publ. Hlth med. Subj., No. 101. H.M.S.O., London.

Monif, G. R. G., Avery, G. B., Korones, S. B., and Sever, J. L. (1965). Lancet, $1,723$.

Nager, F. R. (1952). Pract. oto-rhino-laryng. (Basel), 14, 337.

Ormerod F. C (1960) F. Laryng., 74, 919

Plotkin, S. A. (1964). \%. Amer. med. Ass., 190, 265.

Plotkin, S. A. (1964). F. Amer. med. Ass., 190, 265. Oski. F. A., Hartnett, E. M., Hervada,

Rendle-Short, j. (1964). L Lancet, 2, 373.

Schall, L. A., Lurie, M. H., and Kelemen, G. (1951). Laryngoscope (St. Louis), 61, 99.

Selzer, G. (1963). Lancet, 2, 336.

Sheridan, M. D. (1964). Brit. med. 7., 2, 536.

Stern, H. (1965). Nature (Lond.), 208, 200.

Swan C. Tostevin A. L., Moore, B., Mayo, H., and Black, G. H. B. (1943). Med. Ұ. Aust., 2, 201.

Weller, T. H., Alford, C. A., and Neva, F. A. (1964). Nerv Bngl. Y. Med. 270, 1039.

Wiedemann, H. R. (1964). Lancet, 1, 721.

\title{
Clotting Factors During Oral Contraception : Further Report
}

\author{
L. POLLER,* M.D., M.C.PATH. ; JEAN M. THOMSON,† I.M.L.T.
}

Brit. med. F., 1966, 2, 23-25

A rise of one of the coagulation factors (factor VII) was found to be present in women taking oral contraceptives (Thomson and Poller, 1965). This change was detected from the third month of their course onwards. The significance of the rise in factor VII activity is uncertain. Since factor VII levels are raised during pregnancy and the puerperium (Koller et al., 1952), when the incidence of thrombosis is increased, and since they are raised also in patients with recent thrombosis, this may be an undesirable side-effect.

In the present study we have included data obtained from further investigation of women on a variety of oral contraceptive agents, and have sought to determine how the factor VII and other clotting changes compared with those of normal pregnancy and the puerperium. Observations were made on whether clotting changes differed in the two groups. We have studied women who have been taking oral contraceptives for longer periods to determine whether factor VII changes are cumulative.

Since our first report Hougie et al. (1965) have also described factor $\mathrm{X}$ increases in women taking one type of oral contraceptive preparation (Ortho-Novum) in the United States.

* Consultant Haematologist, Withington Hospital, Manchester.

† Research Technician, Withington Hospital, Manchester.
In the present paper we have therefore included additional factor $\mathrm{X}$ studies in oral contraceptive and control groups.

\section{Method of Study}

Oral Contraceptive Group.-Studies were performed on 97 women taking a variety of oral contraceptives (Anovlar 21, Conovid 24, Gynovlar 9, Lyndiol 8, Norlestrin 13, Ortho-novin 3, Ovulen 11, Volidan 18). Nine women had, on occasion, changed from one preparation to another. The women were tested as previously, as near as possible to their mid-cycle. They attended before the start of their course and then after one month, two months, and three months. Subsequently tests were performed between three and six months, seven and 12 months, and then between one and two years. The final group consisted of women who had been taking one or more types of oral contraceptive continuously for more than two years. The course of only one woman included in this group exceeded three years. Most of the women had in fact begun their course when their first tests were done, and were included in the appropriate group when their results were analysed on a time basis. Two women were excluded because their only tests were performed too late in their menstrual cycle, and a further woman was not included because her tests indicated 